\title{
Psychodynamic Intersectionality and the Positionality of the Group Analyst: The Tension between Analytical Neutrality and Inter-Subjectivity
}

People who shut their eyes to reality simply invite their own destruction, and anyone who insists on remaining in a state of innocence long after that innocence is dead turns himself into a monster

James Baldwin, Notes of a Native Son (1955)

If the word integration means anything, this is what it means: that we, with love, shall force our brothers to see themselves as they are, to cease fleeing from reality and begin to change it.

James Baldwin, The Fire Next Time (1963)

\begin{abstract}
This article proposes the concepts of Psychodynamic Intersectionality and Intersectional Group Analysis by addressing the complex issues of the positionality, or self-location, of the group analyst when working with diverse and intersectional patient groups who have been traumatised by structural oppression, institutional and inter-generational othering. I critique the positionality of the group analyst and the essential intersectional and inter-subjective nature of the role and interventions they may or may not make in the group. The article engages with the need not deny how an understanding of the positionality of the group analyst is central to the clinical frame. Such understanding can assist the clinician to engage with group members who have experienced structural oppression when othering dynamics are inevitably generated in the group matrix. Such dynamics are often being paralleled in the social unconscious and occurrences in society at any given time. I argue that a failure on behalf of the group analyst to reflexively position themselves in relation to powerful phenomena, such as, racism, sexism and homophobia and occurrences in the social unconscious risks a re-traumatising dynamic being paralleled in the group matrix to the determent of group members from marginalised communities.
\end{abstract}

\section{Positionality and Intersectionality}

There is no such thing as a single issue because we do not live single-issue lives.

Audre Lorde (1983)

The link between positionality and Intersectionality can be traced to Sojourner Truth; an African American formerly enslaved woman who made a speech, "Ain't I a Woman," which she delivered at the Women's Rights Convention in 1851. Additionally, the idea of 'double consciousness' was important, as it referred to the African American experience of being tyrannized by the racist gaze that "always looking at one's self through the eyes of a racist white society" and "measuring oneself by the means of a society that viewed them as inferior" (Du Bois, 2008). This set a framework for understanding the positionality of oppressed people in an oppressive world. As a result, it became a very early frame for Intersectionality and alongside race was used to explain the dynamics of gender, colonialism, and xenophobia. This theory laid a strong foundation for other critical theorists such as Kimberly Crenshaw (Crenshaw, 1989). Crenshaw's theorizing of Intersectionality as a framework was grounded in the multiple othering of African American women who simultaneously faced racism and sexism at the 'intersection' of both phenomena. She felt that the black power and feminist movements focused on black men and white women to the exclusion of the unique positionality of black women. This has been now been extended to include other oppressive structures such as homophobia, ageism, masculinity, disability and whiteness (Collins, 2004, Mayes, 2016). Indigenous methodologies also apply positionality to ways of knowing. Also, interconnectedness within kinship groups that believe in 
an interpretation of the world that can only take place via situation and experience with past, present and future blending into each other (Cam Willett, 2005).

Positionality and Intersectionality have become increasingly important in areas, such as, feminist studies, critical race theory, social work and Indigenous studies. Feminist psychoanalytic theorists (Ernst and Maguire, 1987) and the anti-racist theorists (Kareem, 1992, Blackwell, 2005) have critiqued notions of analytic neutrality and the need to consider oppressive social structures. However, these approaches have not become embedded ways of theorizing in the traditional psychodynamic psychotherapies including group analysis. There is perhaps a questionable concern that the principles, or indeed the notion, of 'analytic neutrality' to captures transference enactments during the treatment could be compromized (Gill, 1983, Greenberg, 1986). However, this has also been challenged by contemporary psychoanalysts who advocated for an inter-subjective psychoanalysis (Stolorow et al., 2014). There are even stronger critiques of the notions of analytic neutrality in group analysis...

... when white group analysts write about difference but systemically fail to locate and interrogate themselves as racialized (and gendered) beings, collective defensive and discursive mechanisms are silently in operation. Racism is reproduced. Difference and disturbance are located onto those with less social power. (Kinouani, 2020)

However, few among us would dispute the fact that our impetus to work in any particular psychotherapeutic area, being attracted to particular theoretic paradigms and modalities for our clinical work, is inextricably tied to our personal experiences. Firm reminders by ant-racist polemicists have influenced my own approach and the quote below illustrates this...

I have never lived, nor have any of you, in a world in which race did not matter. Such a world, a world free of racial hierarchy, is frequently imagined or described as dreamscape, Edenesque, utopian so remote are the possibilities of its achievement. (Morrison, 2019)

Positionality, or 'self-location', challenges any notion of 'dreamscape, Edenesque and utopian imaginings, pointing to powerful contextual and relational factors that define and organize personal and professional identities and ways of knowledge generation in any given situation. This includes social science research projects, social work, psychotherapy or in this instance clinical group analysis. Personal identities relating to phenomena, such as, racism, sexism, classism and homophobia comprise power relational positions rather than just identities based on socially constructed othering. In other words, individuals and groups are embedded within context, systems of power and structural oppression and "positionality," meaning that our life experiences and circumstances impact how we see and understand the world around us. This understanding is situational, reflecting degrees of privilege, power and oppression.

\section{My Journey from Intersectionality to Positionality and Group Analysis}

...Racism and homophobia are real conditions of all our lives in this place and time. I urge each one of us here to reach down into that deep place of knowledge inside herself and touch that terror and loathing of any difference that lives here. See whose face it wears...

Audre Lorde (1983)

\section{Personal Journey}

I am a gay man of colour. A person of colour is not a term that I particularly like but it is far more preferable to 'non-white', which implies a lack on the part of the person this label is attached to. I was raised in a working class community in a city that suffered greatly under the recession that gripped the UK at the time. My heritage reflects the waves of African and Irish migration to Liverpool where I was born and grew up. Liverpool was one of the largest slave ports in the world, processing well over a million African slaves. Many local merchants and their ships were involved in slavery from 1700 until its abolition in 1807. As a result, much of the city's wealth in the 18th century came from the trade. 
Slave ships were often built or repaired in Liverpool. By 1795 Liverpool controlled over $80 \%$ of the British and over $40 \%$ of the entire European slave trade.

The buildings and the architecture of the Liverpool docks reflect this slave trading and colonial history. I grew up amongst this history, and as a young child unwittingly played in the streets named after slave traders and colonizers. This racist history has infused my family and community for generations and is a fundamental aspect of my personal matrix and I am, therefore, 'permeated to the core' by this historic 'inter-generational' racist trauma. Indeed, I am descendent of a very old black community who arrived in Liverpool generations ago, comprising of Africans who were slaves, slave traders and sailors, combined with the waves of migration from Ireland. This is a different heritage from the larger but more recent black communities in the UK who arrived from the Caribbean in the 40s, 50s and 60s, often referred to as the Windrush generation.

My appearance honours the combination of my African and Irish heritage and I am accustomed to being referred to as mixed race or bi-racial or, when I was a child and teenager, "The half caste lad." With that said, I consider myself to be a black gay man as I am not white. Although I have the privileges offered by my male gender, I do not have the privilege or the safe borders of whiteness available to me and, since a young child, I have had to negotiate ongoing racism and homophobia that has formed my identity. Unlike my sexuality, my racial otherness is 'visually coded'. It is there to see and available for conscious prejudice and unconscious process, such as, projection and projective identification.

I 'came out' and began to explore my sexuality in the context of a raging virus and homosexuality was a criminal offence as the age of consent was 21 . The AIDS virus was at its peak and primarily homophobic in terms of its rhetoric but also racist, acting to fuel both phenomena. This was the early eighties. Thatcher had come into government two years previously having exploited racist ideas and the popularity of the now defunct National Front with her famous "Britain being swamped by alien cultures" speech. This resonates with what is occurring currently with Brexit and the election of Trump in the US, based on bold racist and xenophobic rhetoric. It was also the time of the 'race riots' that were related to racial tension between the police and the black communities in Britain including Liverpool. A government commissioned investigation into the disturbances (Scarman, 1981) concluded that "Complex political, social and economic factors created a disposition towards violent protest."

My sexuality led to my being ostracized by my family, which left me unanchored and extremely vulnerable. The amount of vicious homophobia and racism I experienced during my adolescence left me 'psychically punch drunk'. The combination of this multiple othering - belonging simultaneously to two very marginalised groups - meant that I spent my mid to late adolescence condemned to playing in the dark; staggering into, but very narrowly avoiding becoming embedded in a criminal subculture. The overwhelming and 'intersectional' phenomena of racism and homophobia underpinned by the powerful sting of the British social class structure are central to my personal matrix and inform my positionality as a social worker, psychoanalytic psychotherapist and group analyst.

Although I do see great value in 'analytic neutrality' to capture transference reactions and to mitigate over-identification, it is unrealistic not to acknowledge that we approach our work within a context of who we are as clinicians and within the oppressive structural contexts in which we and our patients live, love and work. An attempt to deny or minimize powerful phenomena, such as, racism and homophobia in the service of a notion of a purist approach to our clinical work serves to 'erase' extremely wounding factors in the lives of our patients. 'Erasure' undermines the potency of our work to the point that we risk reducing our engagement with group members from marginalized communities, making our psychotherapeutic frame for them almost ridiculous.

\section{-Professional and Psychotherapeutic Journey}

After my social work training in the late 80 s, I worked in Brixton, which, in common with my hometown, is a highly diverse inner city area of London with complex social problems and a history of 
violent protest. My professional lens at this time, viewed human suffering as exclusively sociological and political. It was only with experience and after beginning my own analysis that I appreciated that such formulations of human phenomena fail to address undercurrents of complex unconscious processes. Conversely, my next training in psychoanalytic psychotherapy, although providing me with powerful insights and a frame to understand trauma and different levels of human suffering, did not sufficiently consider structural oppression and its impact on the individual or cultural psyche.

Group analysis and the elaboration of what Foulkes (1964) described as the "foundation matrix" offered something of a third position that brought together my other trainings as a social worker and psychoanalytic psychotherapist. This acknowledged that psyches are, in part, formed out of distinct social, political and cultural circumstances and offers a powerful link that enables simultaneous engagement of the individual, group and society. This combined with an insight on behalf of the group analyst of their own positionality enables formulations at all levels of the matrix. This can address othering processes in the psychotherapy group and offers an anti-oppressive platform for clinical work.

\title{
Clinical Positionality, Psychotherapy and Intersectional Group Analysis
}

\section{...If we are literally permeated by the social dynamics of the community in which we live, the racism, in so far as is it is a feature of our society and its culture, must leave its specific imprint on the individual psyche of us all, black or white.}

(Blackwell, 1994)

\begin{abstract}
'Psychodynamic Intersectionality”, 'Intersectional Group Analysis', 'Clinical positionality' or 'Clinical self-location' always require self-reflexivity and/or curious self-scrutiny about the stance or positioning of the clinician in relation to the social and political context of their psychotherapeutic engagement. Clinical positionality is inescapable. How a specific clinician reflects on it affects powerfully the psychotherapeutic matrix, process and outcome. This extends to the selection and rejection of potential group members, how the group is initially constructed and conducted, to how others are invited to participate are exited, or even expelled, from the group. An understanding of positionality and Intersectionality has the potential to open up an under-interrogated understanding of clinical encounters, through explicit attention to the impact of the characteristics of the group analyst and their understanding of structural oppression on the group matrix.
\end{abstract}

In common with Foulkes (1948) both Intersectionality and Positionality challenge the myth of the mind as an isolated and enclosed entity. Instead, it is conceived of complex relational fields with psychological processes weaving with interpersonal experience. These are shaped and reshaped during the interactional process within different levels of society or indeed inter-subjective relational fields known as the matrix. Implicit in this is a challenge to the stance of analyst having a superior point of view; that is the idea of the 'surgical analyst' felt to put all their own feelings aside as they enter into the analytic session.

If the aim of psychoanalysis, according to Freud (1915) is an ability to love and work, and for Klein (1959) integration, to see the world how it really is, or at least more accurately, and less dominated by unconscious phantasy, then the aim of group analysis is to provide a social context where relational styles that are problematic can be worked out in a context that sustains them, enabling an increased ability to socialize and to mature (Personal correspondence - Aiyegbusi, A). Then what is the stance of the analyst to enable this? It is argued that the notion of the analyst's neutrality and framing of the process in these terms is in itself a structuring and organizing principal of the work and is not in itself at all neutral (Weegmann, 2018).

The notion, therefore, of analytic neutrality is unrealistic; it is at best an aspiration that always involves a degree of failing. It is at these points of failure that rich phenomena and genuine human connection can occur. The notion of a pure and uncontaminated analyst talks to a notion of superiority in positionality. This is coupled with the central aim of the rigorous process of transference interpretation to address unconscious conflicts which potentially erases notions of power, privilege and oppression; that is the impact of the real world and how it structures the individual and collective psyche.

According to Blackwell (1994) even in a group setting, psychotherapists tend to prefer engaging with more individual needs, such as, the Oedipal complex, sibling rivalry and issues of sexuality, self other 
dynamics and internal conflict. They are criticized for being reluctant to discuss the reality of social power relations and oppression, failing to recognize them as socially constructed phenomena that are internalized. This leaves people 'othered' in a particular predicament. This can lead to responses, such as, acquiescence, just keeping quiet to fit in, or insisting on being heard by taking an overly forceful position demanding that issues are addressed. This can provoke negative responses by the other group members and response-making dialogue within the group almost impossible (Aymer, 2002). At such times, instead of exclusively focusing on unconscious processes, which is the view of some group analysts (Garland, 2018), it is incumbent on the group analyst to intervene and not leave the group to manage such destructive dynamics.

Intervention by the analyst is perhaps hindered by a fear of addressing issues of privilege and inequality in the group. This recognition of what is already there but denied, may be felt to create or exacerbate issues of hostility that generates unmanageable anxiety. This is based on an ideal of one common purpose of the group, which fails to see conflicts arising out of societal structures. Instead, they only see them as arising from internal structures which will be transposed and projected into the group and playing out between the group members; in this way, replicating sibling rivalry. This limits the scope of the potency of the analysis and reinforces socially constructed power relations at the expense of some of the group members (Blackwell, 1994).

What then is potentially re-enacted in the group matrix? Particularly, when the clinician is a member of, or strongly identifies, perhaps even inadvertently, with a privileged and dominant or subordinated group and some or none of the group members do not. What does this tell us about the role of the analyst in relation to the powerful unconscious and destructive forces that occur in groups at any given time? According to Garland (2018), if the role of the analyst is to attend primarily to the unconscious functioning of the group, leaving the group to manage themselves, does this not leave some group members at the mercy of complex oppressive dynamics? These dynamics can be generated in groups, which may also parallel occurrences in society and the social unconscious at any given time. Garland (2018) advocates for a thorough personal analysis and training in group dynamics for those running psychotherapy groups, warning of the consequences if they do not. I would also add: Can analysts who cannot demonstrate a sufficient level of reflexivity, who have not had the necessary training and input on issues of diversity and the psychological impact of structural oppression, understand sufficiently complex phenomena and oppressive structures? Are they equipped to navigate the complex task ahead of them in terms of managing unconscious functioning and nurturing the environment essentials (Winnicott and Khan, 1965) to allow people who have been traumatized in such ways to benefit from group analysis?

To begin to answer these questions, it requires an understanding of the positionality of the group analyst against the backdrop of the social unconscious. In addition, the analyst should understand how the group is positioned, or position themselves to act from their valence, internal object relations, attachment styles, evolving narratives and personal characteristics. The analyst is never value free; instead the analyst always speaks on behalf of certain ideas, values, beliefs and interpretations whilst, perhaps inadvertently, silencing others. The analyst, although in line with traditional psychoanalytic principles, aspires to maintain a degree of analytic neutrality., The analyst not only holds an analytic authority but also a positionality toward clinical process and the matrix that they generate for and within the group.

Although I do see great value in 'analytic neutrality' to capture transference reactions and to mitigate over-identification, it is unrealistic not to acknowledge that we approach our work within a context of who we are as clinicians and within the oppressive structural contexts in which we and our patients live, love and work. Nitsun (2009: 329) understands one of the main aims and functions of the group analyst is to facilitate the "democratisation of the group process" which requires the analyst to shift approach to become just another group member. The reality is that the analyst is simultaneously, undoubtedly and essentially different. The analyst's positionality, training and experience, as well as authority, are elements, which other group members do not have. To claim otherwise, Nitsun (2009) suggests, would be disingenuous.

Moreover, Nitsun (2009) suggests, a group's assumption of authority is not a once and for all achievement, "Authority, in the sense of an internal conviction of authority, comes and goes" (2009: :329) and fluctuates and changes throughout life. I would add that, in common with leadership authority, is often taken and not given. This issue has a particular relevance for me as a group analyst 
of colour and also as a gay man. No doubt this will continue to evolve as my experience of conducting groups develops in the context of racism and homophobia reinventing themselves in society. An attempt to deny or minimize the authority or positionality of the analyst in relation to powerful phenomena, such as, racism, sexism and homophobia serves to 'erase' extremely wounding factors in the lives of our patients. This is emphasized in the service of a notion of a purist approach to our clinical work.

\section{Erasure}

'Cultural Erasure' is a how a dominant group oppresses by negating, suppressing and removing the evidence of trauma of what they consider to be a subordinate group of people. It is essential for the dominant group to erase any evidence of the trauma they have inflicted on those othered in order to maintain a positive self-image and not to be persecuted with intolerable depressive anxiety, shame and guilt. Consequently, powerful cultural, group and institutional manic defences come into operation and a great deal of psychic energy will be spent in maintaining the perception of the subordinated group and this will include the erasure of their very real experience of structural oppression. The projections and projective identifications directed toward those that have been subordinated will receive powerful institutional and group re-enforcement.

It is my experience that 'Clinical Erasure' frequently occurs in a psychotherapy context and needs to be managed by the conductor. This can be understood as more than a brutal refusal to 'bear witness' and even more deliberate than 'by-standing' or 'turning a blind eye' (Steiner, 2003, Steiner, 1985). Erasure is a particularly aggressive and insidious form of othering. To erase is to actively make void and dismiss the experience of those from marginalized groups. In it's subtle but nonetheless potent form erasure is "...a mean-spirited absence of reciprocity or mutuality" (Keval, 2018). Erasure is a defence by those with privilege. It is an active refusal to acknowledge very real experience of those marginalized, instead replacing it with a weak rationalization that does not challenge the position of those who do the erasing. The self-image of those with privilege remains intact but there is a betrayal and an attack on the universal human need for connectedness. This is the core driver of othering and leaves the other with a reinforced sense of being the other. This augments their vulnerability to racist, homophobic and sexist projections and structural oppression. In a psychotherapy group this anti-group phenomena (Nitsun, 2014) acts as a powerful driver for re-traumatization and mitigates reparation for people from marginalized groups.

\section{Vignette 1}

Shortly after the recent racist mass murder of 50 people in the mosque attacks in New Zealand by a white supremacist, the only group member of colour began to talk with some anguish about his experience of being hated and the level of racist hate that he has received growing up and his fears presently. He recounted a specific trauma when his brother was severely beaten up by a racist gang carrying baseball bats some years ago. The police at the time had not been swift to respond and no one was brought to justice. Incredibly, the other group members failed to 'bear witness' and did not engage with his anguish. Instead, they began speaking over him about various floods and earthquakes that had caused deaths around the globe. The group at the time were unable to engage with the deliberate racist hate from a white supremacist that fuelled the mass murder. They preferred instead to discuss natural disasters. The talk about floods and earthquakes was perhaps a defence against being flooded and shaken by unwanted responsibility and guilt. The group member's anger at this response was dismissed and it was suggested that he would be happier in an all black group, thereby 'erasing' the very real and painful experience of the group member of colour. They implicitly suggested that he should live in a ghetto as the group were unwilling to process racist trauma with him or, indeed, look at their relationship with their own whiteness. This group member abruptly left the group shortly afterwards.

This vignette demonstrates not only a lack of positive 'mirroring' and 'exchange' but also a brutal refusal to 'bear witness' and a mean spiritedness. When combined, this equates to an overall experience of 'erasure'. There was no direct intervention into the group by the conductor when this incident occurred. In the absence of intervention, the group aggressively made void the person of 
colour's experience and replaced it with their own defensive thinking. Thereby the group avoided selfreflection and empathy, preventing a connection with the person of colour. This left him with a reenforced sense of being the other.

I now discuss a different experience below based on the intervention of the conductor.

\section{Vignette 2}

There had been a homophobic mass murder of 49 people and injury of 53 others in a gay club in the United States. The conductor at the beginning in the group made reference to this hate crime. There was one gay man, Chris, in this mixed group. He had a personal history of homophobic trauma and hate crime, including direct physical assaults to himself, a murder of a close friend, a suicide of another and his own experience of family rejection. This left him vulnerable to sexual exploitation. The gay group member, Chris, said that he had felt very anxious about leaving the house to come to the group that evening. He referred to his fears of homophobia on the way home after the group. He spoke of his feelings of shame of possibly being racist; he felt suspicious of people he saw on the street who may be Muslim. The rest of the group then began a discussion about "nutters with guns" and that transgendered people should not be allowed to use female toilets and changing rooms, seeming to talk over Chris. The group dismissed Chris' protests that as a gay man he was having a particular experience of the homophobic mass murder, as it was in fact people like him that were being specifically targeted and this was rubbing against his own long personal history of homophobic trauma. The group members said that Chris being gay was irrelevant. This had nothing to do with being gay or Muslim as this was an affront to everyone equally and not Chris in particular. Instead, it was primarily about "mad, bad people who had access to assault weapons." A group member sharply said to Chris, "The fact that this happened at a gay club is totally irrelevant, you should stop playing the victim. I'm just as offended as you by the actions of this one lunatic with a gun." Another said, "When you play the victim like that Chris, it is you who are making yourself different from the group and you are doing this to yourself. It is you who marginalises you. Can't you see that? Wouldn't you be happier in a group with just gay men?" Chris seemed silenced, scolded, visibly shaken and upset as he left the session. There was a strong sense that Chris had been punished by the group for being different. In common with the person of colour in the previous vignette, he was effectively being told to go and live in a ghetto.

It is during incidents like these that the positionality and the intervention of the group analyst has the potential to assist the process, but... If the group conductor does not address these issues she cannot realistically assume that anyone else will (Blackwell, 1994). The conductor in this case had his own experience of racism and homophobia and understood his positionality. He became very concerned about the 'erasure' in the group, so made an intervention based on the three R's - Relate, Reflect, and Repair (Schlapobersky, 2016). I discuss this intervention below.

The analyst decided to forego analytic neutrality, unwilling to leave matters to the group. He pointed out that at the end of the previous session, Chris looked quite shaken and that he suspected that this was about what had just been said in last group. The analyst encouraged the group to relate to Chris' raw emotional experience in terms of what he was saying to them; his experience of being hated and how he felt very alone within the group. The analyst invited the group to try to reflect on what was occurring from Chris's his point of view. There was then a discussion about what it meant to be different and have a different point of view. Also, what it might mean to have lived with homophobia ever since being a young child. The analyst pointed out that Chris had also been brave and had said to the group, which was very racially mixed, that he was ashamed of his own racism, which had become active at this time. Chris was inviting the group to engage the dichotomy between being victimized and perpetrating but had been 
accused of playing the victim. He was transparent about his anxiety about being racist and the group still seemed to have struggled to recognise what he was offering and his courage and commitment to the group. He was not, indeed, just playing the victim: he was concerned about his own negative aspects relating to perpetrating racism. This realization was unsettling for Chris and was a significant part of his anguish. This intervention by the conductor seemed to act as a 'Condenser Phenomena' as the group pools its associations and the resultant loosening of group resistance and discharge of unconscious material. This enabled the group members to recognize parts of themselves in each other, leading to increasing recognition of repressed parts of themselves becoming more integrated. The group then seemed less persecuted by Chris' difference and this perhaps related to a lessening of their own feelings of shame and guilt. A guilt which they defended against by locating all the difficulties to Chris' difference and his insistence that this was witnessed by the group. The intervention of the group analyst enabled reparation in the group and established a fuller integration of Chris as a gay man into the group by acknowledging his experience of homophobia.

\section{Conclusion}

'I'll make my report as if I told a story, for I was taught as a child on my home world that Truth is a matter of the imagination. The soundest fact may fail or prevail in the style of its telling: like that singular organic jewel of our seas, which grows brighter as one woman wears it and, worn by another, dulls and goes to dust. Facts are no more solid, coherent, round, and real than pearls are. But both are sensitive.'

Ursula K. Le Guin, The Left-Hand of Darkness

We find ourselves at what I consider to be a significant point in history as we reflect on the present day manifestation of slavery and colonization. Where notions of white supremacy and by standing are at last being called sharply into question. I argue that at this time, more than ever, that regardless of their hierarchal positioning in society, it is essential for group analysts, and indeed all clinicians, to examine the discrepancies between their positionality, theoretical paradigm and practice. Institutional societal structures organize the lives of people from particular groups relating to their position in societal hierarchy against a figure and ground of dominant and subordinate relationships. This extends to the practice of social work, psychotherapy, group analysis and the development of all of the psychological theories in general.

A failure to acknowledge the influence of social privilege, social pathology and the interactive relationship between the individual and marginalized groups, and an often hostile social milieu in terms of how race, class, gender and sexual orientation, contribute to their position in the social hierarchy, and those who they invite into or exclude from their psychotherapy groups makes the psychotherapeutic frame at least limited or perhaps even damaging to some group members. This occurred in vignette one and was mitigated by the intervention of the conductor in vignette two.

This means that clinicians must engage clinically with the social barriers associated with social marginalization that drive the othering that so very dangerously harms people from these marginalised groups when such dynamics inevitably emerge in the matrix. A failure to do so can negatively impact on the matrix generated and the clinical process. There is a danger that the normative social power relationships are re-enacted in the group, which could come to replicate what is oppressive about society. This includes blame, punishment and contempt for the circumstances of the group members from marginalized groups and in extreme cases, a lack of the very necessary analysis of re-traumatizing dynamics as they occur in the group. This, I believe, requires an understanding of equivalence and/or parallel processes, to broader challenges within the world we inhabit. What happens in society happens in the group and is related to how racist and homophobia trauma is enacted, challenged or erased at societal, group and individual levels with all three levels leaking into each other in a feedback loop. I recognize my continuing need to reflect as a group analyst of colour and as a gay man (both internally and externally) upon issues of racist and homophobic trauma and enactments in psychotherapy groups. I must also reflect on my own male privilege and the power it gives me in a patriarchal system. 
Although I come from an under-served and depressed working class community, at this stage in my life, I find myself reaching a high level of education and career attainment, no longer able to consider myself working class. With this said, it is incumbent on me to recognize and share my privilege as I engage with the world as educator and clinician.

Racism, homophobia and sexism underpinned by social class are extremely damaging and powerfully organizing phenomena. If a group member is also from a working class background, this intersection will amplify and make more potent their experience of racism, sexism and homophobia. Those on the receiving end of this intersection require the necessary understanding if group analysts wish to assist them. Understanding positionality can be hard; being open about our connections to our own place in the social hierarchy and privilege is frequently uncomfortable. However, this underscores its importance.

Given the current context of Black Lives Matter and the Me Too movements there is a great urgency for group analysts to interrogate their own privileges, intensions and motivations as clinicians. Without a sufficient degree of reflexivity on behalf of the group analyst, the process risks having less relevance to the communities in which they must serve. Group analysis risks leaning towards simply being an intellectual exercise that satisfies curiosity, instead of what the process needs to be. The process needs to be a deeply emotional, personal, and messy attempt to help patients understand themselves and how they operate in the world.

This is not to suggest that analytic neutrality is meaningless. Rather, I would argue that we are unable to ever be truly objective without understanding our own subjectivities. Analytic neutrality is an ideal that we can never attain but one that we should nevertheless strive for to a realistic degree. Nor do I wish to suggest that positionality and Intersectionality is a panacea for all that is wrong with our clinical work with patients from marginalized groups. But rather, when it comes to assisting group members, the best place to start is always with an interrogation of our own positionality and privilege.

\section{References}

AYMER, C. 2002. The dilemmas for black social work professionals: Therapeutic implications. Journal of Social Work Practice, 16, 15-21.

BLACKWELL, D. 1994. The emergence of racism in group analysis. Group analysis, 27, 197-210.

BLACKWELL, D. 2005. Counselling and psychotherapy with refugees, Jessica Kingsley Publishers.

CAM WILLETT, K. A. 2005. Chapter 4: Putting ourselves forward: location in Aboriginal research. In: S STREGA, L. B. (ed.) Research As Resistance: Critical, Indigenous and Anti-oppressive Approaches. Toronto: Canadian Scholars' Press.

COLLINS, P. H. 2004. Black sexual politics: African Americans, gender, and the new racism, Routledge.

CRENSHAW, K. 1989. Demarginalizing the intersection of race and sex: A black feminist critique of antidiscrimination doctrine, feminist theory and antiracist politics. u. Chi. Legal f., 139.

DU BOIS, W. E. B. 2008. The souls of black folk, Oxford University Press.

ERNST, S. \& MAGUIRE, M. 1987. Living with the sphinx: papers from the Women's Therapy Centre, Women's Press.

FREUD, S. 1915. Observations on transference-love (Further recommendations on the technique of psycho-analysis III).

GARLAND, C. 2018. The groups book: psychoanalytic group therapy: principles and practice, Routledge.

GILL, M. M. 1983. The interpersonal paradigm and the degree of the therapist's involvement. Contemporary Psychoanalysis, 19, 200-237.

GREENBERG, J. R. 1986. The problem of analytic neutrality. Contemporary Psychoanalysis, 22, 7686.

KAREEM, J. 1992. The Nafsiyat intercultural therapy centre: Ideas and experience in intercultural therapy. Intercultural therapy: Themes, interpretations and practice, 14-37.

KEVAL, N. 2018. Racist states of mind: Understanding the perversion of curiosity and concern, Routledge.

KINOUANI, G. 2020. Difference, whiteness and the group analytic matrix: An integrated formulation. Group Analysis, 0533316419883455.

KLEIN, M. 1959. Our adult world and its roots in infancy. Human Relations, 12, 291-303.

LORDE, A. 1983. The master's tools will never dismantle the master's house, na. 
MAYES, T. A. 2016. Understanding Intersectionality between the Law, Gender, Sexuality and Children. Child. Legal Rts. J., 36, 90.

MORRISON, T. 2019. Mouth full of blood: essays, speeches, meditations, Random House.

NITSUN, M. 2014. The anti-group: Destructive forces in the group and their creative potential, Routledge.

SCARMAN, L. 1981. The Brixton Disorders (The Scarman Report). London: HMSO.

SCHLAPOBERSKY, J. 2016. From the couch to the circle: Group-analytic psychotherapy in practice, Routledge.

STEINER, J. 1985. Turning a blind eye: The cover up for Oedipus. International Review of PsychoAnalysis.

STEINER, J. 2003. Psychic retreats: Pathological organizations in psychotic, neurotic and borderline patients, Routledge.

STOLOROW, R. D., BRANDCHAFT, B. \& ATWOOD, G. E. 2014. Psychoanalytic treatment: An intersubjective approach, Routledge.

WEEGMANN, M. 2018. The World within the Group: Developing Theory for Group Analysis, Routledge.

WINNICOTT, D. W. \& KHAN, M. M. R. 1965. The maturational processes and the facilitating environment: Studies in the theory of emotional development, Hogarth Press London. 